\title{
Revisiting Newfoundland Capelin (Mallotus villosus) Recruitment: Is There a Wind Effect?
}

\author{
Gordon Mertz, James A. Helbig, and Eugene Colbourne \\ Science Branch, Department of Fisheries and Oceans \\ Northwest Atlantic Fisheries Centre, P. O. Box 5667 \\ St. John's, Newfoundland, Canada A1C 5X1
}

\begin{abstract}
Previous studies, which have indicated the existence of links between the recruitment of eastern Newfoundland capelin (Mallotus villosus) and wind driven water mass replacement in the coastal zone, were reconsidered from an oceanographer's point of view. It has been assumed that a simple wind index can be usefully employed in predicting capelin recruitment, based on the observation that larval survival requires the presence of favourable coastal water masses whose occurrence is controlled by the wind. It is shown here that a single wind index is unlikely to be suitable for these studies, since the response of water masses to the wind shows great spatial complexity and since coastal temperature records at sites separated by fairly small distances may not be coherent.
\end{abstract}

Key words: Capelin, recruitment, oceanography, wind

\section{Introduction}

The spawning time, hatching period, larval release date and larval survival of east-coast Newfoundland capelin (Mallotus villosus) have all been linked to oceanographic factors (for a summary of the relevant studies see Leggett and Frank, 1990). Spawning dates for capelin in this region appear to be related to the rate of spring-summer warming (Leggett et al., 1984). The hatching time of eggs deposited in the beach gravel is a function of air temperature, water temperature and solar insolation (Leggett et al., 1984). The release of capelin larvae from the beach gravel and the survival of emergent larvae is thought to depend on the presence of favourable water masses in the near shore zone (Leggett et al., 1984). In this paper we review the above mentioned studies from an oceanographic perspective. Some aspects are described of the large scale oceanography and meteorology which are relevant to the ensuing examination, and a discussion of coastal upwelling and its role in determining capelin recruitment along the east coast of Newfoundland is presented.

\section{Oceanography}

Figure 1 shows a map of the study region depicting some important oceanographic features. Figure 2 is a more detailed map, showing some of the major bays which harbour much of the capelin spawning. In Fig. 3 the seasonal wind transition is portrayed. The polar front in Fig. 1 separates the fresh, cold polar waters of the shelf from warmer, saltier Atlantic waters, and this transitional zone corresponds to the offshore branch of the Labra- dor Current. The cold water beneath the warm cap is formed in winter (Keeley, 1981) by the action of cold northwesterly winds (Fig. 3A).

Because of the steep bathymetry of the Grand Banks in the near coastal region, the cold mass, which is found below $50 \mathrm{~m}$ depth in summer, may be encountered very close to shore. Because of the proximity of this mass to the coast, wind driven upwelling can potentially bring very cold water into the near shore area, with possible large consequences for the biota of this zone.

\section{The wind field, upwelling and coastal tempera- ture}

There is a large scale spring transition of the meteorological fields over the Northwest Atlantic. The winter atmospheric pressure field is dominated by the Icelandic Low (Fig. 3A) and, concomitantly, the winds over the Labrador Sea and Grand Banks set from the northwest. Through spring the Icelandic Low weakens, and the Bermuda High becomes the dominant pressure cell in summer (Fig. 3B). The anticyclonic circulation due to the Bermuda High produces a prevailing southwesterly summer wind over the Northwest Atlantic.

Upwelling dynamics. Along the south coast and the Avalon Peninsula of Newfoundland the summer wind field is said to be "upwelling favourable". An along-shore wind blowing with the shore to its left when looking downwind will tend to induce an upwelling circulation. Csanady (1982) provides a comprehensive account of this upwelling phenomenon described in brief below. 


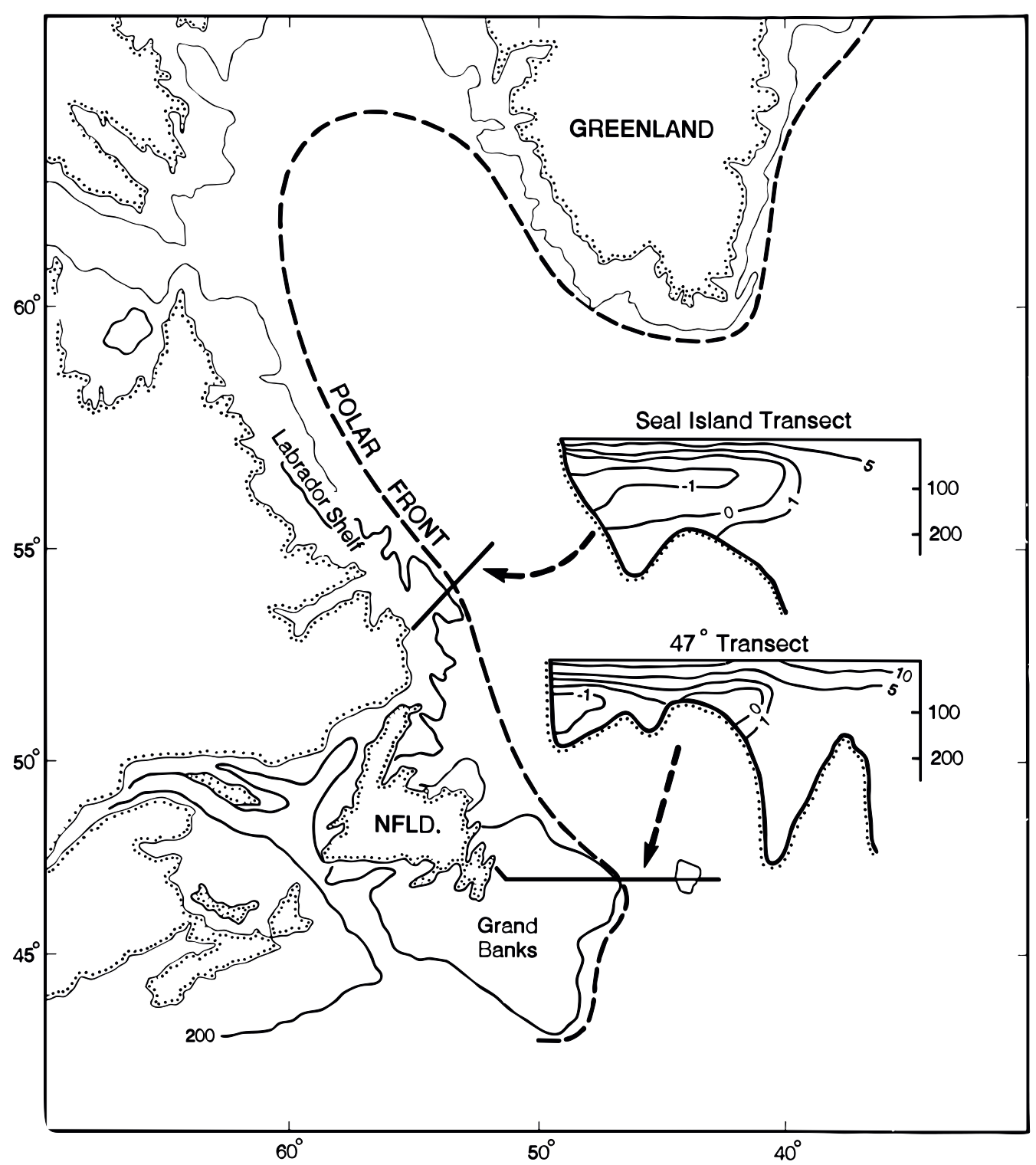

Fig. 1. Map of the study area showing the polar front, dividing cold fresh shelf waters from warmer saltier Atlantic waters. The inserts show two summer temperature sections, illustrating the presence of cold cores over the shelf. These sections are based on long term means (Petrie et al., 1988). The $200 \mathrm{~m}$ isobath is shown.

The wind has a dragging action on the water surface, which is transmitted through the upper part of the water column, the Ekman layer, by frictional stresses. The net effect of the frictional stresses and the Coriolis force (due to the earth's rotation) is to produce a flow which, averaged over the Ekman layer, is directed to the right of the wind, and which is known as the Ekman transport. An upwelling favourable wind produces an Ekman transport directed offshore, causing deep waters to surface near the coast. It is noted that wind blowing perpendicular to the coast (i.e., onshore or offshore) will not induce significant local upwelling or downwelling as the Ekman flux is parallel to the coast in this case.

The Ekman transport $\left(U_{E}\right.$ in units of $\left.m^{2} \mathrm{~s}^{-1}\right)$ is related to the along-shore wind stress ( $\tau$ in units of $\mathrm{Pa}$ ) by the relation

$$
U_{E}=\frac{\tau}{\rho_{W} f}
$$

where $\rho_{w}$ is the density of water and $f$ is Coriolis parameter, representing the effect of the earth's 


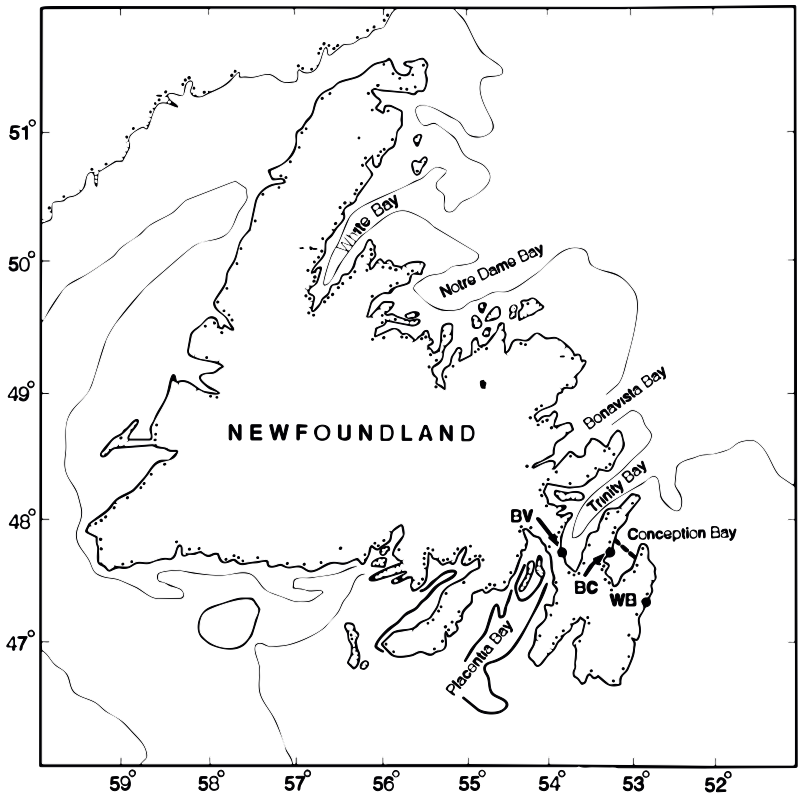

Fig. 2. Map of Newfoundland, showing the major bays. The labels WB, BC and BV designate Witless Bay, Bryant's Cove and Bellevue, respectively. The dashed line across Conception Bay shows the location of the transect where the data presented in Fig. 4 were acquired. The 100 fathom (183 m) contour is shown.

rotation on oceanic motions. For mid-latitudes $f \approx$ $10^{-4} \mathrm{~s}^{-1}$. The wind stress is related to the wind speed by

$$
\tau=\mathrm{CD}_{\mathrm{D}} \mathrm{V}_{\mathrm{w}}^{2}
$$

where $C_{D}$ is the drag coefficient (typically $1.5 \times$ $10^{-3}$, e. g. Large and Pond, 1981), $\rho_{a}$ is the density of air, and $V_{w}$ is the wind speed. For an along-shore wind speed of $5 \mathrm{~m} \mathrm{~s}^{-1}$ (about 10 knots) the wind stress is about $0.04 \mathrm{~Pa}$ and the Ekman transport has a magnitude of about $0.4 \mathrm{~m}^{2} \mathrm{~s}^{-1}$ (a wind stress of $0.04 \mathrm{~Pa}$ is comparable to the along-shore wind stress along the Avalon Peninsula in summer, see Fig. 3B). If the Ekman drift is confined to the zone above the seasonal thermocline, say $30 \mathrm{~m}$ thick, then the average speed of the drift in this layer is a very modest $1.5 \mathrm{~cm} \mathrm{~s}^{-1}$.

For the simple case of steady upwelling favourable winds, blowing parallel to an infinitely long coast, a simple cellular circulation, in a plane perpendicular to the coastline, will prevail. The waters drawn away from the coast by the Ekman drift must be replaced by deeper waters. The width of the upwelling zone is generally taken to be the internal Rossby radius $\lambda_{R}$, (e. g., Yao, 1986), which is a natural trapping scale for motions confined to the upper layer of a stratified fluid. A reasonable value for
$\lambda_{R}$ for the coastal waters of Newfoundland is $5 \mathrm{~km}$ (Yao, 1986; Schneider and Methven, 1988).

The vertical velocity required to compensate for the offshore Ekman drift is $w \approx U_{E} / \lambda_{R}$. For the parameters given in the two preceding paragraphs we have $w \approx\left(0.4 \mathrm{~m}^{2} \mathrm{~s}^{-1}\right) / 5 \mathrm{~km} \approx 7 \mathrm{~m} \mathrm{day}^{-1}$. From this vertical velocity one can calculate the time required for the thermocline to surface (as in Schneider and Methven, 1988), or the magnitude of the temperature changes associated with upwelling or downwelling. The rate of cooling due to upwelling is simply $w(d T / d z)$ where $d T / d z$ is the vertical temperature gradient. These formulae can be used to make comparisons with data: Schneider and Methven (1988) have studied thermal variability at sites adjacent to the Avalon Peninsula, a zone of upwelling favourable winds in the summer. For this area the temperature in summer is typically about $0^{\circ} \mathrm{C}$ at $50 \mathrm{~m}$ depth and about $10^{\circ} \mathrm{C}$ near the surface (e.g. Petrie, et al., 1988) implying a temperature gradient of $0.2^{\circ} \mathrm{C} \mathrm{m}^{-1}$. However, temperature gradients can be much sharper than this near the surface; Schneider and Methven (1988) show temperature gradients of up to $1^{\circ} \mathrm{C} \mathrm{m}^{-1}$ (their fig. 3). Thus, based on our estimates of $w$ and $d T / d z$, we expect wind driven temperature changes at a rate of $1.4^{\circ}$ to $7^{\circ} \mathrm{C}$ day $^{-1}$. In fact Schneider and Methven (1988) report temperature changes of $2^{\circ}$ to $7^{\circ} \mathrm{C} \mathrm{day}^{-1}$, in good agreement with the estimates above. These are very rapid temperature changes (for comparison, the summer warming due to solar input occurs at a rate of about one-tenth of a degree per day) and are induced by the very weak offshore Ekman drift.

It should be emphasized that the oceanographer's picture of upwelling is quite different from that presented in the fisheries literature. Templeman (1966) describes upwelling as a consequence of offshore winds blowing surface waters seaward, drawing deep waters to the surface at the coast, an image also depicted in fig. 2a of Frank and Carscadden (1989). In fact this scheme is not viable from an oceanographic standpoint.

A detailed examination of the response of a stratified ocean to cross-shore (onshore or offshore) winds is given in Csanady (1982), section 3.8. A synopsis of his treatment follows; first we qualitatively describe the underlying principles, and then present a simple quantitative treatment.

An onshore wind drags the sea surface to set up a sea level displacement with its maximum at the coast. The pressure gradient associated with this sea surface slope counters the wind stress and eventually eliminates any flow toward the coast. This suppression of cross-shore motion is the key to 

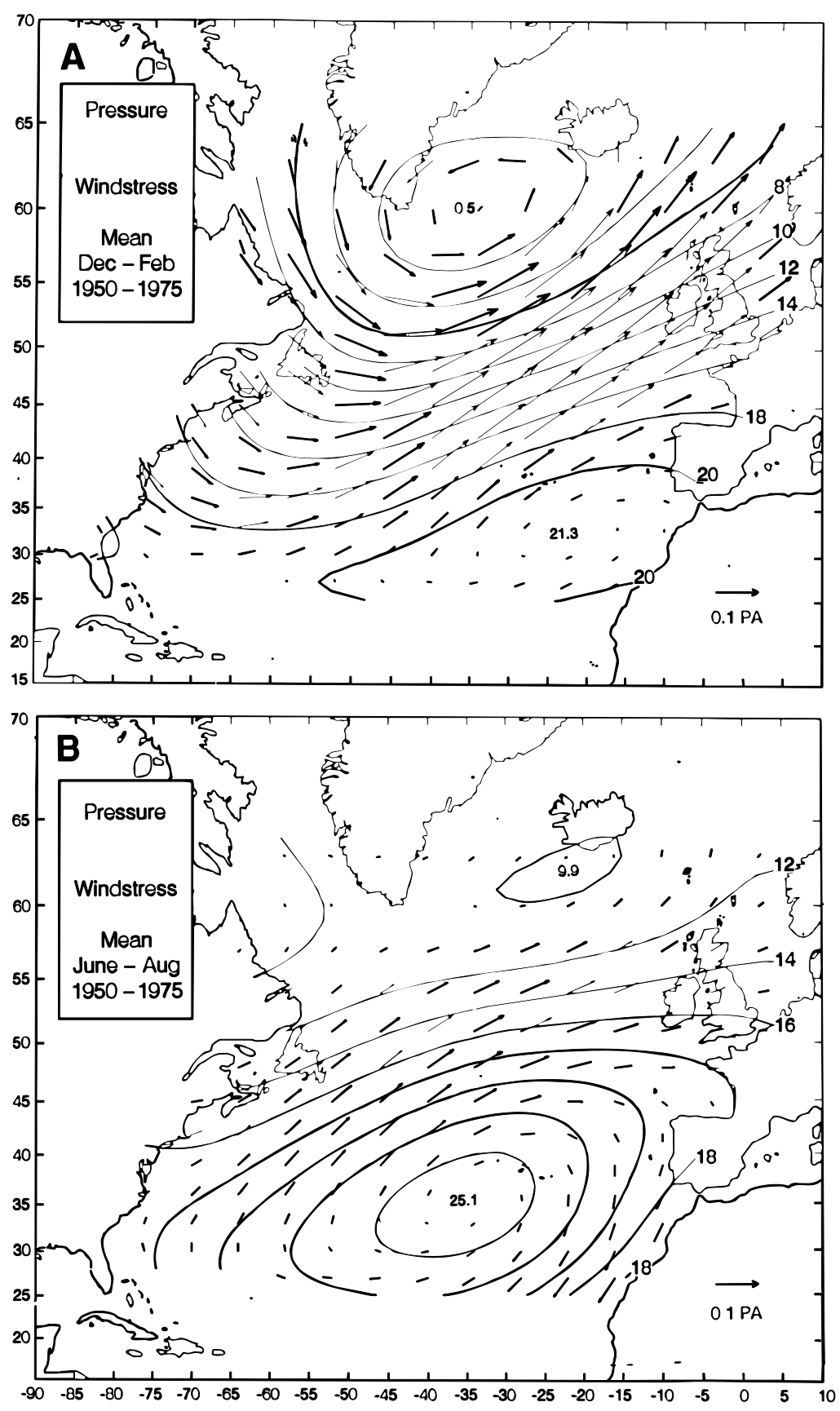

Fig. 3. Mean surface atmospheric pressure (pressure - $1000 \mathrm{mb}$ ) and surface wind stress vectors for the North Atlantic in $(\mathbf{A})$ winter and $(\mathbf{B})$ summer. From Thompson and Hazen (1983)

understanding the relative ineffectiveness of crossshore winds in generating upwelling-type displacements of the thermocline. In a stratified fluid, a pressure compensation generally occurs, whereby the pycnocline adopts the opposite slope to the sea surface, essentially cancelling the pressure gradient due sea surface slope below the pycnocline. (The pycnocline is the depth interval of maximum vertical density gradient and it generally corresponds with the thermocline). Thus, there is generally a pycnocline displacement associated with cross-shore winds, but we will show in the next paragraph that it is not significant compared to that generated by along-shore winds. 
Quantitatively, the balance between the pressure gradient, $g \mathrm{~d} \xi / \mathrm{dx}$ ( $\xi$ is sea level displacement, $\mathrm{g}$ is the gravitational acceleration) with the wind stress is given by

$$
g \frac{d \xi}{d x} \approx g \frac{\xi}{\lambda_{R}}=\frac{\tau}{\rho_{w} h}
$$

where $h$ is the thickness of the upper layer and $x$ is the offshore coordinate. For pressure compensation to occur, the magnitude of the associated displacement of the thermocline $(\eta)$ is given by $\eta \approx\left(\rho_{w} / \Delta \rho_{w}\right) \xi$, where $\Delta \rho_{w}$ is the change of density from the top layer to the bottom layer. From this relation, with equation (3), and the definition, $\lambda_{R^{2}} \equiv g \Delta \rho_{w} h / \rho_{w}$ we can easily show

$$
\eta \approx \frac{\tau}{\rho_{w} \lambda_{R} f^{2}}
$$

Previously, we showed that an along-shore wind creates a vertical velocity of magnitude $U_{E} / \lambda_{R}$; since $\eta=w \times t$ ( $t$ is time elapsed after the onset of the wind) it follows that the thermocline displacement associated with an along-shore wind is $U_{E} t / \lambda_{R}$. From this latter relationship, with equations (1) and (4), it follows that the ratio of thermocline displacement due to one unit of along-shore wind stress to that induced by one unit of cross-shore wind stress is simply $\mathrm{ft}$. Since $f \approx 8.6$ day $^{-1}$, for $t=1$ day we have $\mathrm{ft}=8.6$, the effect of along-shore winds is larger by almost a factor of ten. Of course, for wind pulses of longer duration, the relative importance of alongshore winds is even greater.

The response to along-shore wind discussed above is an example of forced internal Kelvin wave dynamics, which is to say that the motion is aligned with the coast and is in geostrophic balance with the lateral pressure gradient. A most important aspect of motions of this type is their trapping to the coast, the signal decreases exponentially away from the coast with an e-folding length of $\lambda_{R}$. Free internal Kelvin waves are also possible, in addition to the locally-forced class. That is, an oscillation generated at a given site on the coast can be transmitted, as a free internal Kelvin wave, over great distances. These waves are said to be "right-bounded" in that the coast lies to the right of the direction of propagation (in the northern hemisphere). For example, a signal excited at the eastern corner of a bay could be transmitted along the eastern boundary of the bay, experience reflection at the head and then continue along the western side of the bay, eventually exiting the bay at its western corner. Free internal Kelvin waves can obscure, in oceanographic data, the locally forced component of the current or temperature.

Yao (1986) has confirmed the classical picture of wind driven upwelling for Trinity Bay (Fig. 2). Yao
(1986) presented a thorough analysis of the winddriven circulation in Trinity Bay based on data from four current meter moorings. He found that the along-bay component of the wind stress was the principal forcing agent for current fluctuations in the three to seven day period band. A simple model for local wind forcing accounted for many of the features observed. For example, wind driven current amplitudes were found to increase along the eastern shore in agreement with model predictions. Of relevance here, Yao (1986) identified wind driven temperature variations in Trinity Bay, showing that winds out of the bay provoked upwelling along the western side of the bay and downwelling on the eastern side of the bay.

Yao's model did not allow for the influence of free Kelvin waves in the bay, excited by an external source. Yao noted that this was an important limitation, and further noted the occurrence of a large event which could not be explained by the locallyforced model.

There is reasonable consistency among studies of wind forced temperature variations at different sites along the east coast of Newfoundland. Yao (1986) found that the 3 to 7 day period band fluctuations of the along-bay component of the wind could induce local upwelling and downwelling in Trinity Bay. Schneider and Methven (1988) found that the along-shore component of the wind was coherent with the coastal temperature fluctuations in the 3.8 to 6.1 day period band at sites along the Avalon Peninsula. Taggart and Leggett (1987) found that the temperature variations at about a 5 day period in Bryant's Cove (site BC in Fig. 2) responded to the wind along an axis oriented $54^{\circ}$ from true north, which roughly corresponds to the along-bay axis of Conception Bay. Thus, observations generally agree with the simple theory, in that the alongshore component of the wind is seen to be effective at inducing a local upwelling/downwelling signal in coastal temperature.

Upwelling in a bay. Models are always simpler than nature. In particular, the conceptual upwelling models used to explain the emergence of capelin cannot account for variations in local coastal morphology or bathymetry, nor do they take into account the overall domain geometry (i.e. bays, being semi-enclosed, can exhibit much more complex wind driven responses than open coasts). These, sometimes intricate, flow patterns may be revealed by high density oceanographic measurements; we examine a unique set of field data from Conception Bay, featuring high resolution current measurements acquired with an acoustic Doppler current profiler.

Figure 4 shows vertical sections of axial currents (i.e. along the bay axis), temperature and 


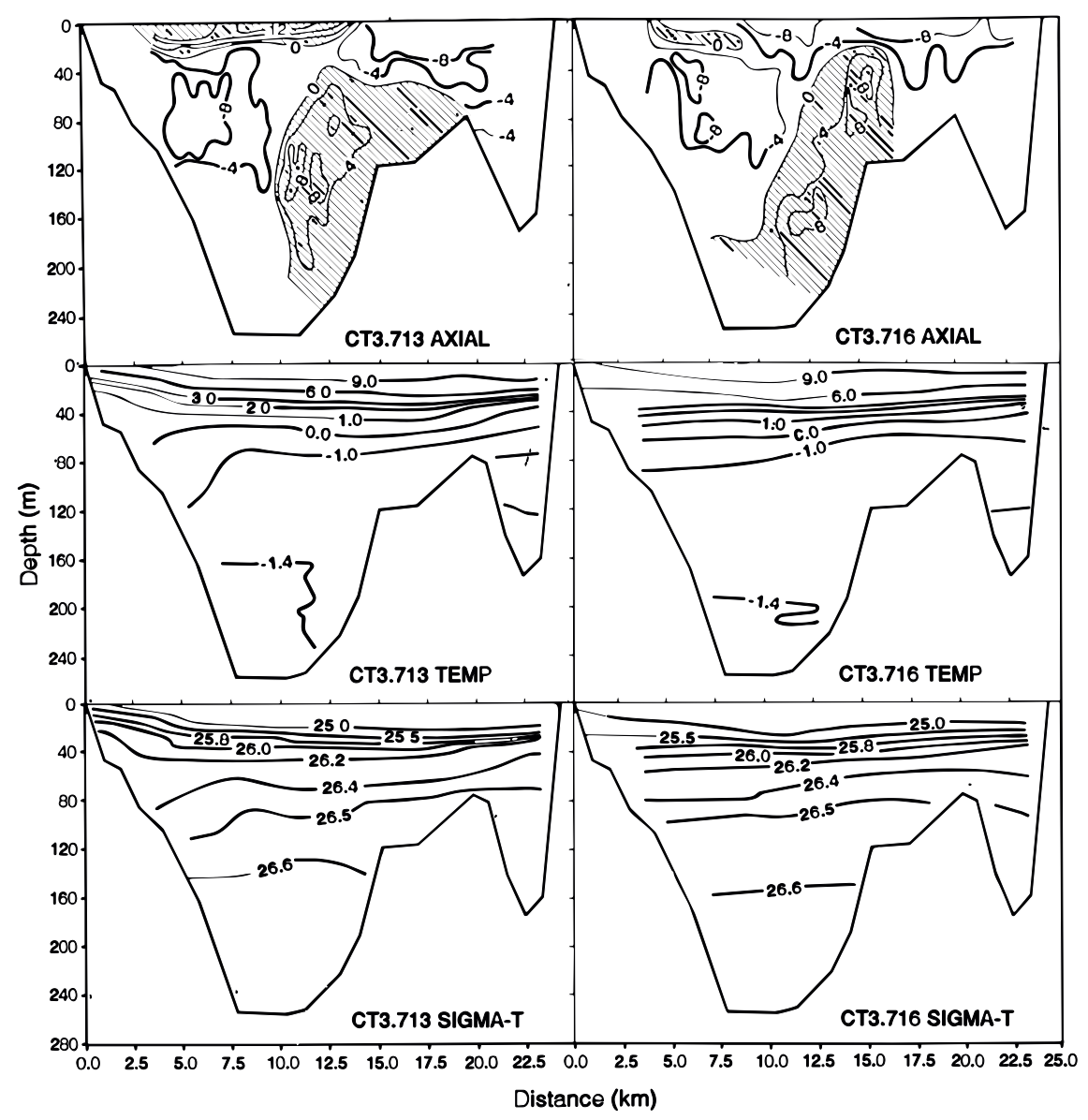

Fig. 4. Sections of axial (along-the-bay) current $\left(\mathrm{cm} \mathrm{s}^{-1}\right)$, temperature $\left({ }^{\circ} \mathrm{C}\right)$ and density (sigmat) for the transect of Conception Bay indicated by the dashed line in Fig. 2. The left panels represent data acquired on 13 July 1990 and the right panels represent data acquired on 15 July 1990. Positive currents are out of the bay. The west side of Conception Bay is on the left hand side.

density on two separate days in Conception Bay (the transect is shown in Fig. 2) during July 1990, generally coinciding with the period of larval emergence. They were chosen to illustrate differences in oceanographic structure between periods of steady out-of-the bay winds (13 July) and periods of in-bay or unsteady winds (15 July). Prior to 13 July, winds were steady at about 10 knots directed out-of-bay, for about one and a half days. Between 13 and 15 July the winds were unsteady in speed and direction. Currents were measured acoustically with a Doppler (ADCP) current profiler. These data were binned and then contoured by eye, in order to smooth the noisy ADCP data. Temperature and salinity were measured at a closely spaced set of stations. It is important to remember in interpreting these figures that they represent a single cross-section of Conception Bay, and do not portray any along-bay differences which may be significant to capelin spawning/survival.
Several features were immediately evident from the transects. Conception Bay exhibited basically a two-layer structure with the upper layer extending to the pycnocline at about $40 \mathrm{~m}$. Under steady out-of-the-bay winds, a strong outflowing surface jet with maximum speeds in excess of $12 \mathrm{~cm} \mathrm{~s}^{-1}$ extended across about half the bay. In fact, there was a net transport of water out of the bay in the upper layer during this period. The lower layer was defined by a pair of opposing "jets", an out-of-thebay flow trapped against the western side of the mid-bay ridge and an into-the-bay flow at mid-depth occupying the western half of the channel to its west.

During the 13 July observation period, the classic upwelling signature was clearly apparent along the western side of Conception Bay, in the sections of temperature and density. Less expected was the small uplifting of isotherms and isopycnals 
along the eastern side, which according to simple theory should be a downwelling zone. That is, both sides of Conception Bay showed evidence of upwelling. In fact, the isopleths sloped downward from the western shore to the region of the mid-bay ridge, after which they once again trended upwards implying the ridge exerts a dynamic influence on the circulation in the bay. This is reasonable in that the wind driven circulation can couple to the bathymetry (e.g. Csanady, 1982).

Conception Bay also displayed a two layer response to the change of wind between the 13 and 15 July observation periods. While the upwelling relaxed in the upper layer along the western side, the isopleths moved upwards toward the surface east of the mid-bay ridge, perhaps itself an upwelling response. The response in the lower layer was of the opposite sense: isotherms and isopycnals moved up in the western sector and sank in the east. Overall, however, there was a deepening of the upper layer in response to stirring by the wind. The upper layer jet all but vanished following the wind reversal, showing that it was directly winddriven.

The lesson to be gleaned from this example is that whereas simple models offer conceptual insight, they are often incapable of describing real field situations. Upwelling is usually a site-specific phenomenon that depends not only on coastal orientation and mean winds but also on local bathymetry and upstream effects. In the present example, simple upwelling theory cannot account for the fact that the bay is closed off at one end or that bathymetrically trapped waves with relevant timescales of a few days are important in the response of the bay to changes in winds, events which could not be explained by the locally-forced model.

\section{Upwelling and the emergence and survival of lar- val capelin}

An important link between oceanography and fisheries is the mechanism described by Leggett et al. (1984, and references therein) governing larval emergence from the beach gravel and survival of larval capelin. It was proposed that the shift from prevailing offshore winds in summer to transient onshore winds brought warmer water to the shore and triggered the emergence of capelin larvae. The warm mass introduced by the onshore winds is relatively free of predators and contains appropriate prey items for the larval capelin, thus promoting their survival. Leggett et al. (1984) used the frequency of onshore winds in the 10 day interval following the hatching of capelin eggs as one input to a regression model designed to hindcast the recruitment time series for Newfoundland capelin.
Leggett et al., (1984) assumed that coastal temperatures along the east coast of Newfoundland respond in unison as the winds shift from southwesterlies (taken to be offshore given the mean orientation of the coast) to northeasterlies. In view of the earlier discussion where it was noted that free internal Kelvin waves can readily corrupt the local wind generated signal, we decided to test this surmise. We re-examined the thermograph data (late June to mid-August, 1982), shown in fig. 2 of Leggett et al. (1984), for five important capelin spawning beaches on the east coast of Newfoundland. To facilitate comparison we removed, using least squares regression, a linear warming trend from the temperature series for each of the locations. We also smoothed the temperature data with a 3-day running mean filter to emphasize the 5-day variability implicated by Leggett et al., (1984) in capelin larval survival.

Figure 5A shows the processed temperature time series at Bryant's Cove (site BC in Fig. 2) plotted with the temperature data from Witless Bay (site WB in Fig. 2). It is clear that these two series are highly coherent, and correlation analysis bears this out $(r=0.75)$. In Fig. 5B we plotted the temperature record at Bryant's Cove with that from Bellevue

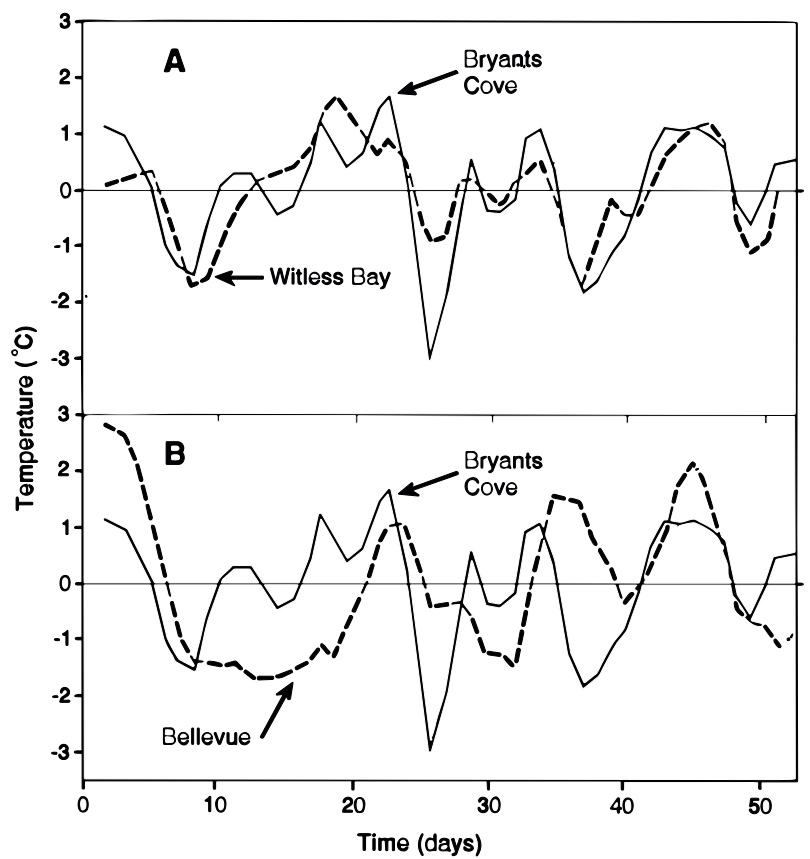

Fig. 5. Detrended and smoothed coastal temperature records from (A) Bryant's Cove and Witless Bay and (B) Bryant's Cove and Bellevue. See Fig. 2 for site locations. Day zero is 25 June 1982. The data were extracted from Leggett et al., (1984). 
(site BV in Fig. 2). It is clear that these records are not strongly related $(r=0.26)$. The correlation between the temperature records at Witless Bay and Bellevue was 0.14 . A correlation of about 0.45 is significant, based on an F-test with $v=18$ degrees of freedom ( $v=2$ months $/ 3$ days -2 , where 2 months is the record length and 3 days is the smoothing window width).

From an oceanographic viewpoint, the results stated in the previous paragraph are expected. Witless Bay and Bryant's Cove both lie on coasts where southwesterly winds will produce upwelling and northeasterly winds will produce downwelling. These two sites should exhibit coherent temperature variations (in response to the wind). In contrast, Bellevue lies at the head of Trinity Bay, where there should be little local response of the temperature field to wind. That is, in a large bay such as Trinity Bay, an out-of-bay wind will force upwelling on the western side, downwelling on the eastern side, and the head of the bay will be a "node" where the response is zero (Yao, 1986). Thus, Bellevue water temperature records should not be expected to be coherent with those from Witless Bay and Bryant's Cove.

It is interesting to note that the temperature fluctuations at Bellevue were as large as those observed at Witless Bay and Bryant's Cove, despite the fact that Bellevue is located at the head of a bay, an area where little local wind driven upwelling is expected. It is clear that there are sources of thermal variability in addition to local wind driven upwelling. In fact, Yao (1986) found that only about $50 \%$ of the variability of currents in Trinity Bay was coherent with the wind. For the temperature variations, it appears (but it is not explicitly stated) that local winds could account for a considerably smaller percentage of the observed variability. The unexplained variability may be due to free internal Kelvin waves excited remotely perhaps by wind forcing or undulations of the Labrador Current.

Temperature records from Eastport, at the head of Bonavista Bay and La Scie, between Notre Dame and White Bays, were also presented by Leggett et al., (1984). We calculated all ten possible inter-correlations for the detrended and filtered temperature series from the five sites examined by Leggett et al., (1984). For locations separated by less than 200 $\mathrm{km}$ (direct distance rather than distance along the coast) all six correlation coefficients were positive, two of the coefficients were significant, and the average of all six coefficients was 0.41 . The fact that all six coefficients were positive may indicate a degree of large scale coherence which is probably imposed by the wind forcing. However, given that the typical correlation coefficient between tempera- ture records at sites separated by less than $200 \mathrm{~km}$ is about 0.4 , only about $16 \%$ of the variance at a typical site can be ascribed to a large scale coherent oscillation.

For locations separated by distances in the range 200 to $400 \mathrm{~km}$, two of the four correlation coefficients were positive, none were larger than 0.29 in magnitude, none were significant, and the average of the four coefficients was -0.05. For separations greater than $200 \mathrm{~km}$ the temperature records were essentially uncorrelated.

Leggett et al., (1984) found, for summer 1982 (the year in which the temperature data discussed above were acquired), that the bursts of larval emergence were highly correlated between Bryant's Cove and Eastport $\left(r^{2}=0.62\right)$. This synchrony was assumed to be a reflection of coherence in the coastal temperature records. Yet, the coastal temperature records at these two sites exhibited weak coherence $\left(r^{2}=0.19\right)$.

Leggett et al., (1984) asserted that there was near synchrony in temperature changes at coastal sites along a $700 \mathrm{~km}$ span of Eastern Newfoundland. Because there are strong temperature fluctuations having periods of several days, it is inevitably true that there will be a degree of synchrony. However, this does not imply that the fluctuations are coherent, nor that they have a common driving force. Indeed the discussion presented above shows that the temperature records at two relatively closely spaced sites, Bellevue and Bryant's Cove, are not coherent.

In summary, we note that our re-examination of the temperature time series presented in Leggett et al., (1984) has shown that the coastal temperature variations in the near five day band at sites separated by distances of more than $200 \mathrm{~km}$ are uncorrelated. This roughly concurs with the analysis of DeYoung and Tang (1989) who showed that winds on the Grand Banks decorrelate when the station separation is greater than about $300 \mathrm{~km}$. In fact coastal temperature even at two nearby sites may not be coherent, particularly if the orientation of the coast differs significantly between the two locales. Therefore, we consider it very surprising that the wind index used by Leggett et al., (1984), the frequency of onshore (northeasterly) winds in the 10 day interval following the hatching period, should significantly enter the regression model used to simulate the capelin recruitment time series, especially since the wind from only one site (St. John's) was used in the analysis. The wind at St. John's may be directly related to coastal temperature along the Avalon peninsula and the west side of Conception Bay. However, correlations between 
St. John's wind and coastal temperature at locations further to the northwest are not likely to be strong.

\section{Discussion}

Capelin recruitment success is correlated to the exchange of water masses between the inshore and offshore regimes (e.g. Leggett et al., 1984; Taggart and Leggett, 1987; Leggett and Frank, 1990). This overview has emphasized the complexity of the coastal oceanography of eastern Newfoundland: given the undulating nature of this coastline, it appears unlikely that any simple model can simulate the behavior of water masses in the near shore zone, over a great reach of coastline.

Many of the important capelin beaches are located in the major bays of eastern Newfoundland. We have seen that the response of a bay to wind forcing may be very complex. While the simple model of Yao (1986) had some success in explaining features of the wind driven circulation of Trinity Bay, much of observed variability could not be explained, and was attributed to external forcing. For Conception Bay we have presented a particularly detailed data set, portraying the very complicated nature of the wind driven motions in this bay. Unexpected features were present, such as the occurrence of upwelling on the eastern shore, under the presence of downwelling favourable winds, and the appearance of a conspicuous flow along the midbay ridge. Garvine (1987) has pointed out that when an estuary or embayment is considerably wider than the internal Rossby radius, $\lambda_{R}$, then complex behavior of the flow field may be anticipated. Given that for the bays of eastern Newfoundland $\lambda_{\mathrm{R}} \approx 5$ $\mathrm{km}$, it is clear that the major bays are much wider than the internal Rossby radius.

Frank and Leggett (1981) convincingly showed that the emergence of capelin larvae from the beach sediments was triggered; they believed that an increase in wave action corresponding to an onshore wind event prompted larval emergence. More recent work (Leggett and Frank, 1990; Frank and Leggett, 1982, 1983) has indicated that larvae respond to changes in near-shore water mass properties rather than wave disturbance. Leggett et al., (1984) asserts that the occurrence of favourable water masses is controlled by the onshore wind, and furthermore, that synchronous changes in this wind component drive the near-simultaneous emergence of capelin larvae on beaches spread over a great span of the coast of eastern Newfoundland. In this paper we have argued that the importance of the onshore component of the wind has been overestimated in these analyses and, moreover, that changes in the near shore water temperature are generally not well synchronized from site to site.
Our conclusion is that the wind index currently used in capelin recruitment studies requires considerable refining. (Note that most of the explainable variance of recruitment in the Leggett et al. (1984) model is due to open-ocean temperature, so that our tendered relegation of the wind to a role of minor importance does not necessarily undermine the utility of this model). As suggested by Taggart and Leggett (1987), the influence of wind on recruitment may be better elucidated by consideration of wind forcing in a specific frequency band.Currently, the wind at St. John's is used to represent coastal temperature; however this is only likely to be a valid proxy for coastal temperature along the Avalon Peninsula and the western side of Conception Bay. A direct approach to determining the water mass type (after the hatching period of capelin eggs) may be called for: thermographs could be installed at a number of closely spaced sites in a selected bay. Alternatively a one-active-layer baroclinic numerical model, forced by observed winds from a number of sites could be used to simulate coastal temperature. Such models have been shown to be useful in studies of upwelling along irregular coasts (e. g. Hua and Thomasset, 1983).

\section{Acknowledgements}

We thank Brian Nakashima and Ransom Myers for beneficial internal reviews of this manuscript. We appreciate the thoughtful comments of Jim Carscadden and two anonymous reviewers.

\section{References}

CSANADY, G. T. 1982. Circulation in the Coastal Ocean, Reidel, Dordrecht, $279 \mathrm{p}$

DeYOUNG, B., and C. L. TANG. 1989. An analysis of Fleet Numerical Oceanographic Center winds on the Grand Banks. Atmosphere-Ocean, 27: 414-427.

FRANK, K. T., and J. E. CARSCADDEN. 1989. Factors affecting recruitment variability of capelin (Mallotus villosus) in the Northwest Atlantic. ICES J. Cons., 45: 146-164.

FRANK, K. T., and W. C. LEGGETT. 1981. Wind regulation of emergence times and early larval survival in capelin (Mallotus villosus). Can. J. Fish. Aquat. Sci., 38: 215-223.

1982. Coastal water mass replacement: its effect on zooplankton dynamics and the predator-prey complex associated with larval capelin (Mallotus villosus). Can. J. Fish. Aquat. Sci., 39: 991-1003.

1983. Multispecies larval fish associations: accident or adaptation? Can. J. Fish. Aquat. Sci., 40: 754-762

GARVINE, R. W. 1987. Estuary plumes and fronts in shelf waters: a layer model. J. Phys. Oceanogr., 17: 1877-1896.

HUA, B.-L., and F. THOMASSET. 1983. A numerical study of the effects of coastline geometry on wind-induced upwelling in the Gulf of Lions. J. Phys. Oceanogr., 13: 678-694.

KEELEY, J. R. 1981. Mean conditions of potential temperature and salinity along the Flemish Cap Section. Can. Tech. Rep. Mar. Environ. Data Serv., 9: 148 p.

LARGE, W. F., and S. POND. 1981. Open ocean momentum flux measurements in moderate to strong winds. J. Phys. Oceanogr., 11: 324-336. 
LEGGETT, W. C., and K. T. FRANK. 1990. The spawning of the capelin. Sci. Amer., 263: 102-107.

LEGGETT, W. C., K. T. FRANK, and J. E. CARSCADDEN. 1984. Meteorological and hydrographic regulation of year-class strength in capelin (Mallotus villosus). Can. J. Fish. Aquat. Sci., 41: 1193-1201.

PETRIE, B., S. AKENHEAD, J. LAZIER, and J. LODER. 1988. The cold intermediate layer on the Labrador and Northeast Newfoundland Shelves, 1978-86. NAFO Sci. Coun. Studies, 12: 57-69.

SCHNEIDER, D. C., and D. A. METHVEN. 1988. Response of capelin to wind-induced thermal events in the southern Labrador Current. J. Mar. Res., 46: 105-118.
TAGGART, C. T., and W. C. LEGGETT. 1987. Wind-forced hydrodynamics and their interaction with larval fish and plankton abundance: a time-series analysis of physical-biological data. Can. J. Fish. Aquat. Sci., 44: 438-451.

TEMPLEMAN, W. 1966. Marine Resources of Newfoundland. Bull. Fish. Res. Board Can., 154: 170 p.

THOMPSON, K. R., and M. G. HAZEN. 1983. Interseasonal changes in wind stress and Ekman upwelling: North Atlantic 1950-1980. Can. Tech. Rep. Fish. Aquat. Sci., 1214: 13 p.

YAO, T. 1986. The response of currents in Trinity Bay, Newfoundland, to local wind forcing. Atmosphere-Ocean, 24: 235-252. 